\title{
Effects of depth and microhabitat on growth and survivorship of juvenile corals in the Florida Keys
}

\author{
Peter J. Edmunds ${ }^{1, *}$, John F. Bruno ${ }^{2}$, David B. Carlon ${ }^{3}$ \\ ${ }^{1}$ Department of Biology, California State University, 18111 Nordhoff Street, Northridge, California 91330-8303, USA \\ ${ }^{2}$ Department of Marine Sciences, University of North Carolina, Chapel Hill, North Carolina 27599, USA \\ ${ }^{3}$ Department of Zoology, University of Hawaii, Honolulu, Hawaii 96822, USA
}

\begin{abstract}
Despite the well known discrimination among substrata by settling larvae of benthic marine invertebrates, there is limited evidence showing that recruits benefit from the microhabitats selected. To explore the fitness consequences of substrate selection by scleractinian corals, this study was designed to test for selective advantages arising from the microhabitat location of juvenile corals on natural substrata on Conch Reef (Florida Keys). Juvenile corals (ca. 2 to $40 \mathrm{~mm}$ diameter) were censused for density and microhabitat at 14,17, 20 and $26 \mathrm{~m}$ depth, and a subset were tagged to measure growth and survivorship. Microhabitats were scored as exposed (upward facing), vertical or cryptic, and the results were analyzed first for all taxa combined, and second by life-history strategy in order to contrast 2 ecologically distinct groups (i.e. brooders versus broadcasters). The majority ( $>53 \%$ ) of juveniles occupied exposed microhabitats at all depths, with the remainder mostly in vertical instead of cryptic microhabitats at $\leq 17 \mathrm{~m}$, and in cryptic instead of vertical microhabitats at $\geq 20 \mathrm{~m}$ depth. Overall, juvenile distribution was unrelated to life history, and the abundance of brooders and broadcasters was largely similar across depths (regardless of microhabitat). Despite clear evidence of non-random distribution of juvenile corals, their growth and survivorship were statistically indistinguishable among the microhabitats or depths. The disparity between these results and evidence that coral larvae actively select specific microhabitats for settlement could reflect (1) a strong size-dependency of the fitness consequences of microhabitat, (2) a consequence of reef degradation such as a modification of the selective value of microhabitats, or (3) reduced exploitation competition for settlement locations caused by low rates of coral recruitment.
\end{abstract}

KEY WORDS: Juvenile corals $\cdot$ Microhabitats $\cdot$ Depth gradient $\cdot$ Scleractinian

\section{INTRODUCTION}

A central theme in the study of benthic community structure is the elucidation of the roles of pre- and post-settlement events in determining population dynamics (Gosselin \& Qian 1997, Morgan 2001, Underwood \& Keough 2001). In some systems, 'supply-side' ecology - reflecting spatio-temporal variability in larval supply-plays a large role in determining the abundance of local adult populations (Gaines \& Roughgarden 1985, Underwood \& Keough 2001), while in others post-settlement mortality is more important (Pineda et al. 2002, Delany et al. 2003, see also Menge 2000), particularly at high settlement den- sities (Raimondi 1990, Morgan 2001). Given the potential importance of both pre- and post-settlement events in determining benthic community structure, the challenge now is to identify the conditions under which larvae become more (or less) important than recruits in determining population dynamics (Morgan 2001). Part of this process involves testing for selective advantages in occupying different settlement locations (Raimondi 1990), exploring how these might vary depending on the environmental context, and determining to what extent the 'wrong' location has detrimental consequences for recruits (Strathmann et al. 1981).

For tropical reef corals, there is overwhelming evidence of acute substrate discrimination by their larvae 
(Richmond 1997, Raimondi \& Morse 2000, Carlon 2002, Baird et al. 2003), and a striking and general pattern of recruits favoring specific settlement orientations that vary among depths (Birkeland et al. 1981, Rogers et al. 1984, Harrison \& Wallace 1990, Carlon 2001). At shallow depths $(<\mathrm{ca} .12 \mathrm{~m})$, coral recruits typically are found on cryptic crevices or vertical surfaces, but at greater depth, recruitment typically is higher on horizontal/exposed surfaces. Three mechanisms that could drive these patterns are: (1) depth-dependent shifts in larval supply to these surfaces; (2) larval preferences that change with depth; and (3) differential survivorship among microhabitats that changes over depth. While the first hypothesis has yet to be evaluated, several experimental studies designed to test the roles of larval behavior and post-settlement survivorship in generating patterns of recruit distribution have now been carried out. Most indicate that larvae settle in specific microhabitats (Mundy \& Babcock 1998, Raimondi \& Morse 2000), with microhabitat preferences varying among species (Mundy \& Babcock 1998). For example, on the Great Barrier Reef, Babcock \& Mundy (1996) found that the larvae of 2 coral species prefer vertical and cryptic orientations in the shallow depths of their distribution, but exposed and vertical orientations in the deeper portion. In later experiments, Mundy \& Babcock (1998) demonstrated that light intensity and spectral quality mediated settlement patterns of larvae from 5 coral species that were consistent with the patterns of vertical distribution of the adults in the field.

Such specific settlement behavior suggests that natural selection could partially affect larval settlement behavior/choice. In the case of corals, patterns of larval behavior and recruit distribution suggest that fitness (e.g. survivorship of juvenile corals or conceivably, the fecundity of adult colonies) ultimately varies with microhabitat at the time of settlement, and that the intensity and direction of natural selection among microhabitats changes with depth. If correct, then the distribution of juvenile corals indicates that microhabitat surfaces in shallow water should be ranked cryptic $>$ vertical > exposed by decreasing fitness, while in deeper water the ranking is reversed. When the orientation of newly settled coral recruits has been manipulated using settlement tiles located at different depths, these predictions generally hold true when fitness is measured as early survivorship (Babcock \& Mundy 1996, Mundy \& Babcock 2000). Several sources of mortality could explain these patterns. At shallow depths, competition for space between corals and turf algae is potentially more intense on exposed compared to vertical or cryptic surfaces (Birkeland 1977, Birkeland et al. 1981), and the accumulation of sediment on exposed surfaces represents a significant deterrent to recruitment (Bak \& Engel 1979, Gilmour 1999). Also, the indirect effects of herbivorous fish and invertebrates may indiscriminately kill coral recruits on exposed surfaces (Sammarco 1980). In deep water cryptic habitats, intense competition for space together with high growth rates of suspension-feeding invertebrates (sponges, bivalves, bryozoans, etc.) is thought to reduce coral settlement and growth (Carlon 2001), but this hypothesis has not been tested.

While previous studies of coral recruitment are in general agreement with the ranking of fitness among microhabitats at shallow and deep depths, studies utilizing settlement plates are likely to bias the effects of competitive interactions that occur between young corals and adjacent flora and fauna. These interactions are minimized because settlement plates typically are deployed in the field devoid of the natural assemblages of potential interacting species, and therefore the coral larvae that settle during short deployments rarely encounter other sessile taxa. This bias maybe inflated in cryptic habitats, where free space for coral settlement and growth is always at a premium (Buss \& Jackson 1979, Jackson \& Winston 1982). Thus measurements of growth and survivorship during the first few months post-deployment are unlikely to reflect the ecological dynamics on most natural surfaces.

The purpose of this study was to examine the distribution of juvenile corals on a Caribbean reef and compare rates of growth and survivorship among microhabitats and depths. We measured these parameters on established juvenile colonies ranging in size from the smallest we could detect (ca. $2 \mathrm{~mm}$ diameter) to $40 \mathrm{~mm}$ diameter, and operationally defined orientations as exposed (upward-facing), vertical or cryptic to provide an ordinal description of the continuous gradient of microhabitat variation. This size range of juveniles was necessary to provide the replicate corals necessary for a comparison of fitness correlates among naturally occurring microhabitats. Because important biological traits differ between corals with brooding versus broadcasting life-history strategies (Bak \& Engel 1979, Harrison \& Wallace 1990, Richmond 1997), we first analyzed our data for all taxa combined, then separately by life-history strategy when sample sizes permitted. Our analyses were completed at intermediate to deep depths (14 to $26 \mathrm{~m}$ ) on Conch Reef, which in 1995 (when the study began) was dominated by macroalgae $(\geq 33 \%$ cover$)$, crustose coralline algae, turf algae and bare space combined ( $\geq 13 \%$ cover), and small amounts of scleractinian coral $(\leq 6 \%$ cover) (P. J. Edmunds unpubl. data). While our results provide unequivocal evidence of non-random distribution of juvenile corals among 3 types of microhabitats across a $12 \mathrm{~m}$ depth range, surprisingly they reveal few advantages for juvenile corals to favor any one microhabitat over another. 


\section{MATERIALS AND METHODS}

In 1995, saturation diving from the Aquarius undersea habitat was used to census and tag corals to a depth that normally would be intractable through surface diving. The following year, the quicker task of censusing tagged corals for growth and survivorship was carried out with surface-supported diving. Surveys were carried out over 4 depth intervals (12-15 m, 16-19 m, 20-22 $\mathrm{m}$ and 24-29 m depth), hereafter described as 14, 17, 20 and $26 \mathrm{~m}$ depths, respectively.

Surveys of juvenile corals. Juvenile corals were defined as small colonies without the fractured surfaces characteristic of asexual reproduction (Highsmith 1982). Although the growth rates of small corals are variable (Van Moorsel 1988, Edmunds 2000), a representative growth rate of ca. $12 \mathrm{~mm} \mathrm{yr}^{-1}$ (Bak \& Engel 1979, Van Moorsel 1988) suggests that the juveniles in the present study probably were $\leq 3.5 \mathrm{yr}$ old.

Juvenile corals were counted in $0.25 \mathrm{~m}^{2}$ quadrats that were placed randomly along transects at each depth. Algae and sediments were brushed aside to locate corals, and colonies were identified to genus (a few to species as described below) and their microhabitat recorded. Montastraea was recorded as $M$. cavernosa and $M$. annularis-complex (including $M$. annularis, $M$. faveolata and $M$. franksi) because of the ecological importance of this genus, and the high abundance of $M$. cavernosa. Microhabitats were scored to distinguish among juveniles on exposed (upward-facing), vertical (vertical and steeply sloping surfaces on coral rock) and cryptic (the outer $5 \mathrm{~cm}$ of cracks, crevices and overhangs) surfaces. The $5 \mathrm{~cm}$ restriction for cryptic microhabitats ensured that most juvenile corals encountered were hermatypes.

The availability of the 3 microhabitats was not assessed in 1995-96 due to the difficulties of quantifying these resources. To gain an insight into their abundance, in 2002 the 3-dimensional structure of the reef was quantified as topographic complexity (TC) (Rogers et al. 1982) by conforming a fine chain to the substratum and dividing the conformed length by the linear distance ( $\mathrm{n}=10$ per depth). We used TC as a proxy for the availability of microhabitats with the assumption that it was proportional to reef rugosity. This approach underestimates microhabitat availability because the chain cannot be conformed to the narrowest fissures or the interstices of cavities within the reef.

Survivorship and growth. The growth and survivorship of juvenile corals was determined by marking them with aluminum tags and censusing them $1 \mathrm{yr}$ later. The tags were attached to vacant substratum adjacent to each coral using underwater epoxy (Z-Spar A788). Multiple species were tagged in exposed, vertical and cryptic microhabitats at 14, 17 and $26 \mathrm{~m}$ depth to determine the effect of microhabitat and depth on success. Corals were selected for tagging as encountered while swimming along each depth contour, but were not tagged at $20 \mathrm{~m}$ due to time limitations. The diameter of tagged colonies was measured with calipers $( \pm 0.1 \mathrm{~mm})$ in 1995 , and $1 \mathrm{yr}$ later the tags were relocated and the living corals measured. Growth was expressed as change in diameter, and survivorship as the percentage of live corals versus either dead in place or lost from the substratum.

Statistical analyses. The distribution of juvenile corals was analyzed first for all taxa combined, and then for the common brooding (Porites and Agaricia) and broadcasting (Montastraea and Siderastrea siderea; $S$. radians was not found at the study site) taxa. Although the densities were positively skewed, the frequency distributions were assumed to be normal based on the central limit theorem (Sokal \& Rohlf 1995), and were compared among depths with 1-way ANOVA using $\log (x+1)$ transformed data. The distribution and taxonomic composition of juvenile corals among depths and microhabitats were analyzed using $\chi^{2}$-contingency tables (expected frequencies $\geq 6$ ).

The effects of depth and microhabitat on survivorship were analyzed with log-linear models (Sokal \& Rohlf 1995). Analogous to multi-factor ANOVA, log-linear analysis of categorical data can determine the relative importance of multiple explanatory variables and permits the detection of interactions among them. Unlike ANOVA, the terms of interest are the interactions themselves (e.g. associations) between explanatory variables, rather than their individual effects. In our case, we were interested in the effects of 2 explanatory variables, depth and microhabitat, on the response variable of survivorship. A log-linear analysis proceeds by testing a more complex model (one with more terms) against a simpler model to determine the significance of including the term of interest in the model. The criterion of parsimony is used for model selection. First we were interested in knowing if either depth or microhabitat had significant effects on whether juvenile corals were alive or dead after 1 yr. Second, if both variables were significantly associated with survivorship, we wanted to know if either depth or microhabitat could explain additional variation in survivorship beyond that attributed to the competing variable. For example, if the depth at which juvenile corals were growing was associated with survivorship, could microhabitat within a depth explain any additional variation in survivorship? We estimated loglikelihood statistics $(G)$ for each model, and to test for significance between models.

Growth rates of juvenile corals were compared among depths and microhabitats with an analysis of covariance (ANCOVA) using depth and microhabitat as fixed factors and initial size as the covariate; a sec- 
ond ANCOVA using initial size as the covariate was used to compare growth among depths and life histories. For both ANCOVAs, the statistical assumption of homogeneity of slopes among groups was tested with a preliminary analysis. Topographic complexity was compared among depths with a 1-way ANOVA.

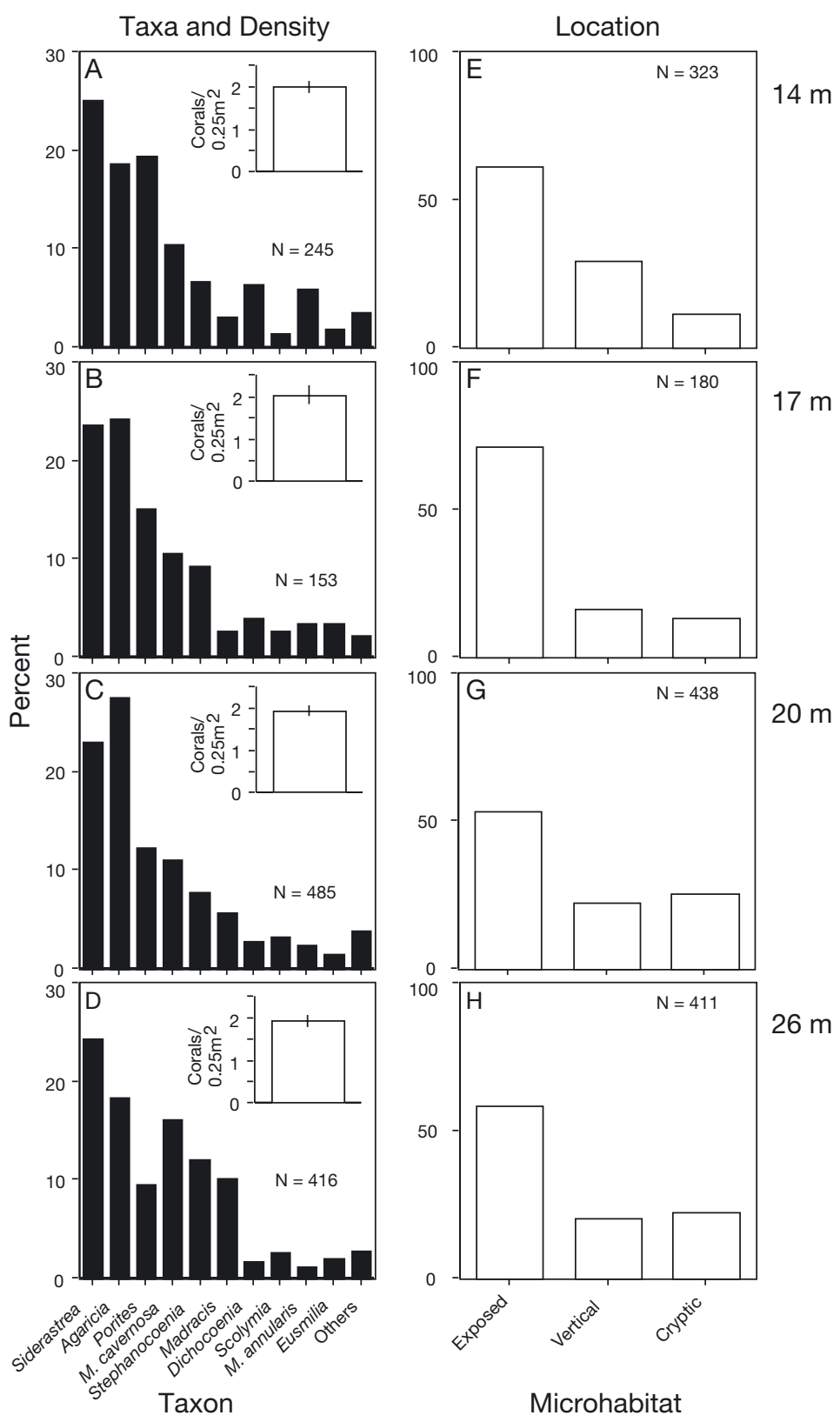

Fig. 1. Taxonomic composition, density and location of juvenile corals at 4 depths on Conch Reef, Florida. (A-D) Taxonomic composition of juvenile corals ( $\leq 40 \mathrm{~mm}$ diameter). Values are shown by genus, except for Montastraea cavernosa and $M$. annularis-complex. Inset bar graphs show the mean density of juvenile corals (pooled by taxon; \pm SE) based on sample sizes (no. of quadrats) of 162 at $14 \mathrm{~m}, 88$ at $17 \mathrm{~m}, 227$ at $20 \mathrm{~m}$, and 212 at $26 \mathrm{~m}$ depth. (E-H) The percentage of juvenile corals found in exposed, vertical or cryptic microhabitats. $\mathrm{N}=$ number of juvenile corals
All statistical analyses were completed with Systat 9.0 software, and assumptions of ANOVA (normality and homoscedasticity) were tested through an analysis of the residuals.

\section{RESULTS}

\section{Surveys of juvenile corals}

Between 88 and 227 quadrats were censused at each depth, and 1352 juvenile corals from 17 genera were found. Mean densities (pooled by microhabitat and taxon) ranged from 1.9 to 2.1 corals $0.25 \mathrm{~m}^{-2}$ (Fig. 1A-D), with some quadrats containing 10 juveniles at all depths, but densities did not vary significantly among depths $(F=$ 0.421, df $=3,685, \mathrm{p}=0.738$ ).

Most of the juvenile corals $(\geq 74 \%$; range 69 to $78 \%$ at each depth) were Siderastrea siderea, Agaricia, Porites, or Montastraea (83\% of which were $M$. cavernosa), with the remainder split among 13 genera, each representing $\leq 12 \%$ of the corals (Fig. 1A-D). The relative abundance of each taxon varied significantly among depths $\left(\chi^{2}=49.001, \mathrm{df}=\right.$ $12, \mathrm{p}<0.001$ ) (Table 1), because of small departures from expectations in multiple cases (i.e. there was no conspicuous distribution pattern among depths). The majority ( $\geq 53 \%$ ) of juvenile corals were found in exposed microhabitats at all depths (Fig. 1E-H), but the relative number in vertical versus cryptic microhabitats reversed between $\leq 17$ and $\geq 20 \mathrm{~m}$ depth. These trends were significant $(4 \times 3$ contingency table; $\chi^{2}=44.884$, df $=6, \mathrm{p}<$ 0.001), largely because relatively more corals were found in vertical microhabitats at $14 \mathrm{~m}$, exposed microhabitats at $17 \mathrm{~m}$, and cryptic microhabitats at $20 \mathrm{~m}$ depth. Relatively few juveniles were found in cryptic microhabitats at $14 \mathrm{~m}$, and in vertical and cryptic microhabitats at $17 \mathrm{~m}$ depth (Fig. 1). The 3 microhabitats were common at all depths (P. J. Edmunds pers. obs.), but measurements of topographic complexity suggested that vertical and cryptic microhabitats were slightly more abundant at $14 \mathrm{~m}$ : TC differed significantly among depths $(F=9.101$, df $=$ $3,36, \mathrm{p}<0.001)$ and was greater at $14 \mathrm{~m}$ (TC $=0.75 \pm 0.02$; mean $\pm \mathrm{SE}$ ) compared to the other 3 depths (mean $\mathrm{TC}=0.60$ to 0.65 ; Tukey's HSD post hoc comparisons $\mathrm{p} \leq$ $0.007)$. Given that the 3 microhabitats were 
Table 1. Abundance of juvenile corals compared (A) among depths and taxa, and (B) among depths and life-history strategies; based on surveys completed in 1995 on Conch Reef, FL. The life-history comparison was accomplished by pooling Porites and Agaricia for the brooders, and Montastraea and Siderastrea for the broadcasters. Results of $\chi^{2}$ analyses are shown, and demonstrate that the relative abundance of juvenile coral taxa varies among depths, although there is no significant variation by life-history strategy

\begin{tabular}{|c|c|c|c|c|c|c|}
\hline & Group & $14 \mathrm{~m}$ & $17 \mathrm{~m}$ & $20 \mathrm{~m}$ & $26 \mathrm{~m}$ & Total \\
\hline (A) All corals & Siderastrea & 78 & 57 & 109 & 96 & 340 \\
\hline$\chi^{2}=49.001, \mathrm{df}=12$ & Agaricia & 61 & 39 & 119 & 76 & 295 \\
\hline \multirow{4}{*}{$\mathrm{p}<0.001$} & Porites & 66 & 24 & 43 & 38 & 171 \\
\hline & Montastraea & 51 & 22 & 57 & 70 & 200 \\
\hline & Other taxa & 67 & 38 & 110 & 131 & 346 \\
\hline & Total & 323 & 180 & 438 & 411 & 1352 \\
\hline (B) By life-history & Brooding & 127 & 63 & 162 & 114 & 466 \\
\hline$\chi^{2}=6.114, \mathrm{df}=3$ & Broadcasting & 129 & 79 & 166 & 166 & 540 \\
\hline$p=0.106$ & Total & 256 & 142 & 328 & 280 & 1006 \\
\hline
\end{tabular}

available at all depths, possibly with more cryptic and vertical surfaces at $14 \mathrm{~m}$ depth (based on high TC values), the distribution pattern of juvenile corals indicates microhabitat preference that varies slightly among depths.

The analysis of juvenile corals by life-history strategy showed that the relative abundance of brooders and broadcasters was statistically indistinguishable among depths when microhabitats were combined (Table 1). While the absolute density of juveniles did not vary significantly among depths for broadcasters $(F=0.514, \mathrm{df}=3,685, \mathrm{p}=0.673)$, it did for brooders $(F=$ 2.713 , df $=3,685, \mathrm{p}=0.044)$, and there were slightly higher mean densities of brooded juveniles at $14 \mathrm{~m}$ $\left(0.78 \pm 0.08\right.$ corals $\left.0.25 \mathrm{~m}^{-2}[ \pm \mathrm{SE}, \mathrm{n}=162]\right)$ compared to the other depths $\left(<0.72\right.$ corals $\left.0.25 \mathrm{~m}^{-2}\right)$; none of the post hoc comparisons (Tukey' HSD) were significant ( $p>0.171$ ). At 14, 20 and $26 \mathrm{~m}$, the relative abundance of brooding and broadcasting corals was independent of microhabitats $\left(2 \times 3\right.$ contingency tables; $\chi^{2}<3.542$, $\mathrm{df}=2, \mathrm{p}>0.170$ ), but varied among microhabitats at $17 \mathrm{~m}\left(\chi^{2}=12.855, \mathrm{df}=2, \mathrm{p}=0.002\right)$. In general, lifehistory strategy had no substantial effect on microhabitat preference, but at $17 \mathrm{~m}$ brooders favored cryptic and vertical microhabitats and broadcasters favored exposed microhabitats.

\section{Survivorship and growth}

Of the 437 aluminum tags deployed in 1995, 249 were located in 1996: $43 \%$ were found at $14 \mathrm{~m} \mathrm{(n} \mathrm{=}$ $134), 57 \%$ at $17 \mathrm{~m}(\mathrm{n}=138)$ and $49 \%$ at $26 \mathrm{~m}(\mathrm{n}=165)$. The corals most frequently tagged (69 to $79 \%$ of the corals at each depth) were the most common on the reef (Table 1), namely Siderastrea siderea, Porites, Montastraea cavernosa and Agaricia. These taxa accounted for $21-28 \%, 4-19 \%, 14-29 \%$ and $9-22 \%$ of the tagged corals at each depth, respectively, and contingency tables demonstrated that the relative abundance of the dominant taxa tagged were similar among microhabitats at each depth $\left(\chi^{2} \leq 12.521\right.$, $\mathrm{df}=8$, $p>0.129)$. The statistical analyses of survivorship and growth were limited due to small sample sizes, and contrasts therefore were completed with pooled taxa. Only in the case of growth were sufficient replicates available for a life-history contrast.

Survivorship ranged from 95\% (n = 21) in cryptic microhabitats at $26 \mathrm{~m}$ depth, to $69 \%(\mathrm{n}=13)$ on vertical microhabitats at $14 \mathrm{~m}$ depth. Log-linear analyses detected no significant effect of depth (D) or microhabitat (M) on the survivorship (S) of juvenile corals after 1 yr (Table 2). Because models that included either variable (D or $M$ ) did not provide a better fit to the data than a model of independence between all 3 variables $(D+M+S)$, we did not continue to test more complex models. Although there was a weak trend for survivorship in exposed and vertical microhabitats to increase with depth (Fig. 2A-C), this effect was not statistically significant.

Table 2. Log-linear analyses of a multidimensional contingency table comparing the survivorship $\left(S_{\text {; }}\right.$ alive or dead) of juvenile corals among depths $(\mathrm{D} ; 14,17$ and $20 \mathrm{~m})$ and microhabitats $(\mathrm{M}$; exposed, vertical or cryptic). Value of the $G$ statistic $(G)$ shown; refer to Fig. 2A-C for sample sizes (no. of corals). Since no effect of depth or microhabitat was detected, more complex models were not tested

\begin{tabular}{|lrrc|}
\hline Model & \multicolumn{1}{c}{$G$} & df & $\mathrm{p}$ \\
\hline $\mathrm{D}+\mathrm{M}+\mathrm{S}$ & 14.751 & 12 & \\
D + M + S + MS & 10.572 & 10 & \\
Microhabitat & 4.180 & 2 & 0.124 \\
D + M + S & 14.751 & 12 & \\
D + M + S + DS & 12.085 & 10 & \\
Depth & 2.670 & 2 & 0.264 \\
\hline
\end{tabular}



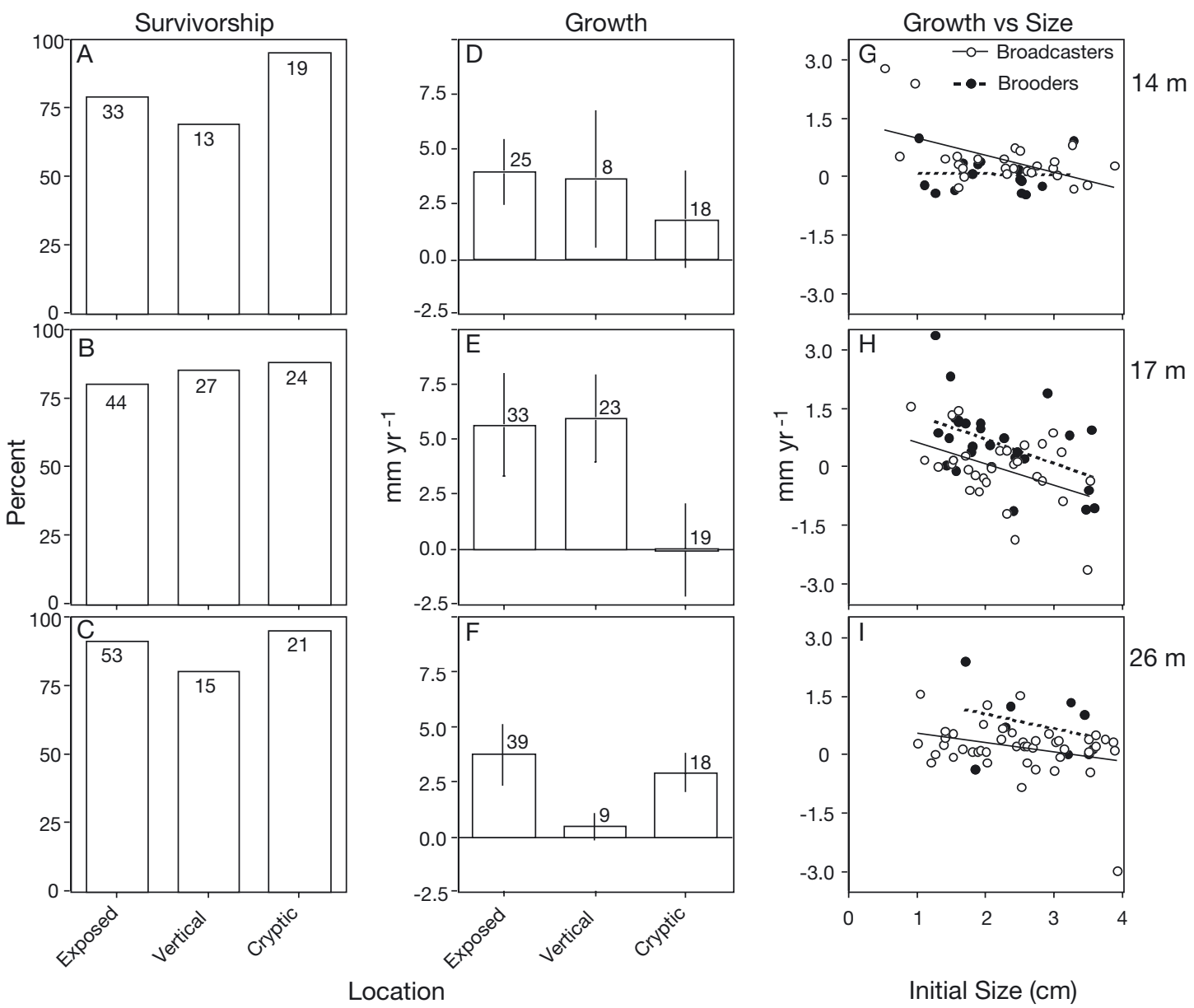

Fig. 2. (A-C) Annual survivorship, (D-F) mean growth rates $( \pm$ SE) (sample sizes shown within or above each bar), and $(G-I)$ the relationship between growth and size for brooding and broadcasting juvenile corals (pooled by taxon) in exposed, vertical and cryptic microhabitats at 3 depths on Conch Reef (corals were not tagged at $20 \mathrm{~m}$ depth)

Growth rates were calculated for 192 corals: 51 were at $14 \mathrm{~m}, 75$ at $17 \mathrm{~m}$ and 66 at $26 \mathrm{~m}$ depth, and the majority were Agaricia (15\%), Montastraea cavernosa $(23 \%)$, Porites $(11 \%)$, or Siderastrea siderea $(26 \%)$. Growth rates were variable among colonies, ranging from $-3.1 \mathrm{~mm} \mathrm{yr}^{-1}$ (i.e. shrinkage) to $+6.5 \mathrm{~mm} \mathrm{yr}^{-1}$, and $25 \%$ of the colonies shrank or remained the same size. Growth rates did not vary significantly among microhabitats or depths, and there was no significant depth $\times$ microhabitat interaction (Table 3 ). When analyzed by life history, growth was significantly affected by a depth $\times$ life history interaction, and also varied significantly between life histories but not among depths (Table 4). Thus, although mean growth rates generally were lower in deeper water, in cryptic microhabitats at $17 \mathrm{~m}$, and vertical microhabitats at $26 \mathrm{~m}$ depth (Fig. 2D-F), these trends are not significant. Conversely, growth rates of brooding and broadcasting corals varied in dissimilar ways across depths, largely because brooders grew slightly faster than broadcasters at 17 and $26 \mathrm{~m}$ depth, but not at $14 \mathrm{~m}$ depth.

\section{DISCUSSION}

The most interesting outcome of this study is the demonstration that juvenile corals do not benefit significantly from occupying specific microhabitats on natural substrata, yet they are distributed in a nonrandom pattern with regards to microhabitat. In other words, the majority of juvenile corals between 14 and $26 \mathrm{~m}$ depth on Conch Reef are found on exposed substrata, even though this microhabitat offers no growth or survivorship advantage over co-occurring cryptic and vertical microhabitats. This result is inconsistent with numerous studies of larval behavior and postsettlement survivorship in benthic marine invertebrates, including reef corals (Morgan 2001), as well as patterns of recruitment that point to the selective pressure for settlement in optimal locations. For reef corals, such effects presumably have contributed to the depth-dependent ranking of exposed, cryptic and vertical microhabitats based on their suitability (e.g. Birkeland et al. 1981). 
Table 3. ANCOVA comparing the growth rate $\left(\mathrm{mm} \mathrm{yr}^{-1}\right)$ of juvenile corals among depths (14,17 and $26 \mathrm{~m}$ ) and microhabitat (exposed, verti$\mathrm{cal}$ and cryptic) using the initial colony size $(\mathrm{mm})$ as a covariate. The data met the ANCOVA assumption of homogeneity of slopes among groups $(F=1.119, \mathrm{df}=8,172, \mathrm{p}=0.353)$

\begin{tabular}{|lrrrrr|}
\hline Source & SS & df & MS & \multicolumn{1}{c|}{$F$} & p \\
\hline Depth & 0.163 & 2 & 0.082 & 0.141 & 0.869 \\
Microhabitat & 0.777 & 2 & 0.389 & 0.671 & 0.513 \\
Depth $\times$ Microhabitat & 1.507 & 4 & 0.377 & 0.650 & 0.627 \\
Initial size & 16.667 & 1 & 16.667 & 28.767 & $<0.001$ \\
Error & 104.285 & 180 & 0.579 & & \\
\hline
\end{tabular}

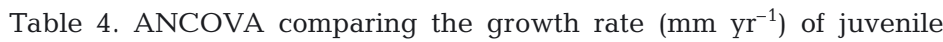
corals among depths $(14,17$ and $26 \mathrm{~m}$ ) and life histories (brooders versus broadcasters) using the initial colony size $(\mathrm{mm})$ as the covariate. To achieve a life-history comparison, brooders were represented by Porites and Agaricia, and broadcasters by Montastraea and Siderastrea. The data met the ANCOVA assumption of homogeneity of slopes among groups $(F=1.129, \mathrm{df}=5,141, \mathrm{p}=0.348)$

\begin{tabular}{|lrrrrr|}
\hline Source & SS & df & MS & \multicolumn{1}{c|}{$F$} & p \\
\hline Depth & 2.741 & 2 & 1.370 & 2.677 & 0.072 \\
Life history & 2.245 & 1 & 2.245 & 4.386 & 0.038 \\
Depth $\times$ Life history & 8.014 & 2 & 4.007 & 7.827 & 0.001 \\
Initial size & 13.144 & 1 & 13.144 & 25.674 & $<0.001$ \\
Error & 74.745 & 146 & 0.512 & & \\
\hline
\end{tabular}

potential selective value of microhabitats for juvenile corals. For example, Gardella \& Edmunds (1999, 2001) demonstrated that juvenile corals are dependent upon the flow fields created by their microhabitats to stimulate their metabolism, and Mundy \& Babcock (1998) demonstrated that the survival of coral recruits from 2 species was affected by a depth $\times$ orientation (upper versus lower surface of tiles) interaction at Orpheus Island. Similarly in Bonaire, Raimondi \& Morse (2000) found that the growth and survival of newly settled Agaricia humilis was strongly affected by orientation, whether or not the corals were exposed to fish grazers and, over a longer term, by depth. To date, however, no studies have monitored individual coral recruits long enough to establish a cause-and-effect relationship between larval settlement and adult distribution.

With these general patterns as a context for our study, we anticipated that juvenile corals on Conch Reef would be distributed with a preference for certain microhabitats (Fig. 1), but we did not expect to find that this pattern would be relatively independent of depth, that the density and taxa of juvenile corals would vary to only a small extent across a $12 \mathrm{~m}$ depth range, or that the juvenile fitness would not vary detectably among micro-

The underlying premise of the present study is that invertebrate larvae discriminate among settlement surfaces (Chia \& Bickell 1978, Harrison \& Wallace 1990, Morse \& Morse 1996) with beneficial consequences (Denley \& Underwood 1979, Babcock \& Mundy 1996, Morgan 2001). As a result, recruits typically are distributed in a non-random pattern (Morgan 2001), such as exhibited by coral recruits on both natural surfaces (Bak \& Engel 1979) and settlement tiles (Rogers et al. 1984, Babcock \& Mundy 1996, Mundy \& Babcock 2000). Based on this premise, the classic depth-dependent distribution of reef corals (Goreau 1959), and the switch in the distribution of coral recruits from cryptic to exposed microhabitats in deeper water (Birkeland 1977), is likely due in part to larval substrate selection. To what extent post-settlement processes modify patterns initiated by settlement of coral larvae is unclear (Raimondi 1990, Dunstan \& Johnson 1998), but regardless of post-settlement events, there is strong inferential evidence that the selection of suitable settlement surfaces by coral larvae plays an important role in mediating the distribution of adults (Mundy \& Babcock 1998, 2000, Raimondi \& Morse 2000, Carlon 2002). Moreover, several studies have used manipulative experiments to reveal the habitats and depths. The growth and survivorship of juvenile corals were also unrelated to whether the species was a brooder or broadcaster. Other studies have also failed to find a depth effect on the survivorship of coral recruits (Fig. 2), including Smith (1997) who also worked on Conch Reef (between 10 and 30 m), Bak \& Engel (1979) in Curaçoa, and Mundy \& Babcock (2000) on the Great Barrier Reef. These and other studies provide support for the greater relative importance of larval delivery and settlement rather than post-settlement events in determining the distribution of adult corals (Mundy \& Babcock 2000). On Conch Reef, however, our methods did not reveal striking vertical zonation for either adult (data not shown) or juvenile corals perhaps because coral cover was so low $(\leq 6 \%)$ - but in the absence of such patterns, interpreting the depthindependent survivorship of juvenile corals as support for the role of larval settlement in mediating the distribution of adults is problematic.

By not supporting the hypothesis that juvenile corals are predictably successful in specific microhabitats across a depth profile, our results from Conch Reef are inconsistent with the patterns emerging from a number of (but not all) studies. In other words, this study suggests that the success (i.e. growth and survivorship) 
of juvenile corals on Conch Reef currently is determined by events operating on spatial scales larger than those conventionally associated with microhabitats that differ in their suitability for coral recruits (e.g. Mundy \& Babcock 2000, Raimondi \& Morse 2000). There are a number of hypotheses that might account for this discrepancy, but a parsimonious explanation focuses on the aspects of our work that are relatively unusual compared to most studies that have addressed coral recruitment, particularly those completed before the degradation of Caribbean reefs accelerated towards the end of the 20th century. Namely, that we assessed coral recruitment on natural surfaces instead of settlement tiles, and worked at intermediate-todeep locations on a reef that is substantially degraded compared to those first described quantitatively (e.g. Goreau 1959) (although now Conch Reef is similar to many other Caribbean reefs [Gardener et al. 2003]). These differences are not trivial, because natural surfaces typically are more complex than settlement tiles in terms of rugosity and the flora and fauna associated with them, and are likely to interact with coral recruits in more complex ways. For example, the 3dimensional structure of cryptic microhabitats on natural surfaces is very different from the undersides of settlement tiles that are typically described as cryptic, and undoubtedly have very different flow fields. Given the complexity of reef substrata, it is possible that the settlement cues found on natural surfaces overwhelm the effects of orientation that are prominent when artificial settlement tiles are deployed. It is also likely that the depth of our surveys influenced the outcome of our analyses, because the shallowest depth $(14 \mathrm{~m})$ is relatively deep compared to the depth range across which the microhabitat preference of juvenile corals has often been reported to change from cryptic to exposed and vertical microhabitats (Birkeland 1977, Tougas \& Porter 2002).

The degraded condition of Caribbean coral reefs (Gardener et al. 2003), including those in the upper Florida Keys (Chiappone \& Sullivan 1996, 1997, Porter et al. 2002) where Conch Reef is situated, may also have affected our analyses by eroding the 'traditional' depth-dependent advantages of microhabitat selection by juvenile corals. For instance, there is less potential for the success of juvenile corals to vary among microhabitats and depths due to differential interactions with other components of the community after the reef has been uniformly degraded to $\leq 6 \%$ coral cover, and is dominated by macroalgae in virtually all locations (this study; Chiappone \& Sullivan 1996, 1997). Moreover, the low densities of juvenile corals on Conch Reef (cf. Bak \& Engel 1979, Rogers et al. 1984, Edmunds 2000), particularly at intermediate-to-deep sites, may ensure an ample supply of satisfactory settlement loca- tions and avoidance of exploitation competition, which can force recruits to settle in poor locations where they have a low chance of surviving (Raimondi 1990). Under such conditions, larval supply (i.e. pre-settlement events) may be more important that post-settlement events in determining the distribution of recruits (Gaines \& Roughgarden 1985). Additionally, a paucity of juvenile corals also increases the methodological difficulties of statistically testing for patterns in the density or success of recruits and distinguishing genus- or species-level effects. Regardless of these potential methodological problems, the possibility that ongoing and widespread reef degradation (Knowlton 2001, Gardner et al. 2003) could affect the fundamental process determining post-settlement success for reef corals has important consequences that should be studied further.

Finally, an evaluation of why juvenile corals on Conch Reef apparently do not benefit from the microhabitats they select must be couched in the context surrounding the completion of our research. First, our inferences concerning larval selection of microhabitats assume that the microhabitats were equally available at all depths, as indicated by our anecdotal observations. It was not possible to directly quantify microhabitat availability, but measurements of the topographic complexity (TC) between 17 and $26 \mathrm{~m}$ depth lend support to this assertion (TC did not vary among these depths); although the reef was slightly rougher at $14 \mathrm{~m}$, this did not correspond to shifts in the distribution of juvenile corals. Thus, with ample microhabitats, the unequal distribution of juvenile corals probably reflects the outcome of systematic processes including substrate selection. Second, it was beyond the scope of this study to test the hypothesis that coral spat benefit from larval substrate selection, and therefore we cannot discount the possibility that the biological significance of microhabitat selection is manifest in coral spat, that is individuals (often with only a single polyp) smaller than those we surveyed. Indeed, based on a review of 30 studies of age-specific mortality in benthic marine invertebrates (Gosselin \& Qian 1997), the majority $(>80 \%)$ of recently settled individuals die within $120 \mathrm{~d}$, and therefore the putative benefits of settlement microhabitat are likely to be realized on a similar time scale. A rigorous experimental investigation of microhabitat availability and extremely young corals (i.e. wk-mo old) will require detailed analyses of surface characteristics (i.e. microhabitats) of reef substrata, together with the quantification of naturally occurring coral spat. These tasks will be hugely time consuming and perhaps intractable to study (but see Dunstan \& Johnson 1998) as tropical reefs become increasingly depleted of coral cover (Gardner et al. 2003). 
Acknowledgements. This is a research project of the University Corporation pursuant to subcontracts UNCW 95-10 and 96-19 from the National Undersea Research Center at the University of North Carolina at Wilmington, NOAA Grant NA96RU-0260. Additional support was provided by CSUN, and the research was completed under permits from the Florida Keys National Marine Sanctuary (FKNMS [UR] 11-95 and 11-96). We thank S. Miller, and the staff at the National Undersea Research Center, Key Largo, for providing a productive Aquarius mission. This project would not have been possible without our saturation team-K. Jones, D. W. Swanson and S. Grace-our surface team leader D. G. Gardella, and our surface support divers A. Alfaro, T. Prude and S. V. Vollmer. We are grateful to J. A. Idjadi and S. Lee for measuring topographic complexity in 2002, and 3 anonymous reviewers for providing comments that improved an earlier draft of this paper. This is contribution number 121 of the CSUN Marine Biology Program.

\section{LITERATURE CITED}

Babcock R, Mundy C (1996) Coral recruitment: Consequences of settlement choice for early growth and survivorship in two scleractinians. J Exp Mar Biol Ecol 206:179-201

Baird AH, Babcock RC, Mundy CP (2003) Habitat selection by larvae influences the depth distribution of six common coral species. Mar Ecol Prog Ser 252:289-293

Bak RPM, Engel MS (1979) Distribution, abundance and survival of juvenile hermatypic corals (Scleractinia) and the importance of life history strategies in the parent community. Mar Biol 54:341-352

Birkeland C (1977) The importance of rate of biomass accumulation in early successional stages of benthic communities to the survival of coral recruits. Proc 3rd Int Coral Reef Symp 2:15-21

Birkeland C, Rowley D, Randall RH (1981) Coral recruitment patterns at Guam. Proc 4th Int Coral Reef Symp 2:339-344

Buss LW, Jackson JBC (1979) Competitive networks: nontransitive competitive relationships in cryptic coral reef environments. Am Nat 113:223-234

Carlon DB (2001) Depth-related patterns of coral recruitment and cryptic suspension-feeding invertebrates on Guana Island, British Virgin Islands. Bull Mar Sci 68:525-541

Carlon DB (2002) Production and supply of larvae as determinants of zonation in a brooding tropical coral. J Exp Mar Biol Ecol 268:33-46

Chia FS, Bickell LR (1978) Mechanisms of larval attachment and the induction of settlement and metamorphosis in coelenterates: a review. In: Chia FS, Rice M (eds) Settlement and metamorphosis of marine invertebrate larvae. Elsevier, New York, p 1-12

Chiappone M, Sullivan KM (1996) Distribution, abundance and species composition of juvenile scleractinian corals in the Florida reef tract. Bull Mar Sci 58:555-569

Chiappone M, Sullivan KM (1997) Rapid assessment of reefs in the Florida Keys: results from a synoptic survey. Proc 8th Int Coral Reef Symp 2:1509-1514

Delany J, Myers AA, McGrath D, O'Riorda, RM, Power AM (2003) Role of post-settlement mortality and 'supply-side' ecology in setting patterns of intertidal distribution in the chthamalid barnacles Chthamalus montagui and C. stellatus. Mar Ecol Prog Ser 249:207-214

Denley EJ, Underwood AJ (1979) Experiments on factors influencing settlement, survival, and growth of two species of barnacles in New South Wales. J Exp Mar Biol Ecol 36:269-293

Dunstan PK, Johnson CR (1998) Spatio-temporal variation in coral recruitment at different scales on Heron Reef, southern Great Barrier Reef. Coral Reefs 17:71-81

Edmunds PJ (2000) Patterns in the distribution of juvenile corals and coral reef community structure in St. John, US Virgin Islands. Mar Ecol Prog Ser 202:113-124

Gaines S, Roughgarden J (1985) Larval settlement rate: A leading determinant of structure in an ecological community of the marine intertidal zone. PNAS 82:3707-3711

Gardella DG, Edmunds PJ (1999) The oxygen microenvironment adjacent to the tissue of the scleractinian Dichocoenia stokesii and its effects on symbiont metabolism. Mar Biol 135:289-295

Gardella DG, Edmunds PJ (2001) The influence of flow regime and morphology on boundary layer characteristics in Scleractinian corals. J Exp Mar Biol Ecol 256:279-289

Gardner TA, Cote IM, Gill FA, Grant A, Watkinson AR (2003) Long-term region-wide declines in Caribbean corals. Science 301:958-960

Gilmour J (1999) Experimental investigation into the effects of sediment on fertilization, larval survival and settlement in a scleractinian coral. Mar Biol 135:451-462

Goreau TF (1959) The ecology of Jamaica coral reefs: species composition and zonation. Ecology 40:67-90

Gosselin LA, Qian PY (1997) Juvenile mortality in benthic marine invertebrates. Mar Ecol Prog Ser 146:165-182

Harrison PL, Wallace CC (1990) Reproduction, dispersal and recruitment of scleractinian corals. In: Dubinsky Z (ed) Ecosystems of the world, Vol 25. Coral reefs. Elsevier, New York, p 133-207

Highsmith RC (1982) Reproduction by fragmentation in corals. Mar Ecol Prog Ser 7:207-226

Jackson JBC, Winston JE (1982) Ecology of cryptic coral reef communities. I. Distribution and abundance of major groups of encrusting organisms. J Exp Mar Biol 57:135-147

Knowlton N (2001) The future of coral reefs. Proc Natl Acad Sci 98:5419-5425

Menge BA (2000) Recruitment vs postrecruitment processes as determinants of barnacle population abundance. Ecol Monogr 70:265-288

Morgan SG (2001) The larval ecology of marine communities. In: Bertness MD, Gaines SD, Hay ME (eds) Marine community ecology. Sinauer Associates, Sunderland, p 159-181

Morse ANC, Morse DE (1996) Flypapers for coral and other planktonic larvae. Bioscience 46:254-262

Mundy C, Babcock R (1998) Role of light intensity and spectral quality in coral settlement: implications for depthdependent settlement? J Exp Mar Biol Ecol 223:235-255

Mundy C, Babcock R (2000) Are vertical distribution patterns of scleractinian corals maintained by pre- or post-settlement processes? A case study of three contrasting species. Mar Ecol Prog Ser 198:109-119

Pineda J, Riebensahm D, Medeiros-Bergen D (2002) Semibalanus balanoides in winter and spring: larval concentration, settlement, and substrate occupancy. Mar Biol 140: 789-800

Porter JW, Kosmynin V, Patterson KL, Porter KG and 13 others (2002) Detection of coral reef change by the Florida Keys coral reef monitoring project. In: Porter JW, Porter KG (eds) The Everglades, Florida Bay, and coral reefs of the Florida Keys: an ecosystem sourcebook. CRC Press, Boca Raton, p 749-769

Raimondi PT (1990) Patterns, mechanisms, consequences of variability in settlement and recruitment of an intertidal barnacle. Ecol Monogr 60:283-309

Raimondi PT, Morse ANC (2000) The consequences of complex larval behavior in a coral. Ecology 81:3193-3211 
Richmond RH (1997) Reproduction and recruitment in corals: critical links in the persistence of reefs. In: Birkeland C (ed) Life and death of coral reefs. Chapman \& Hall, New York, p 175-197

Rogers CS, Suchanek T, Pecora F (1982) Effects of Hurricanes David and Frederic (1979) on shallow Acropora palmata reef communities: St. Croix, USVI. Bull Mar Sci 32:532-548

Rogers CS, Fitz HC, Gilnack M, Beets J, Hardin J (1984) Scleractinian coral recruitment patterns at Salt River Submarine Canyon, St. Croix, U.S. Virgin Islands. Coral Reefs 3:69-76

Sammarco PW (1980) Diadema and its relationship to coral spat mortality: grazing, competition, and biological disturbance. J Exp Mar Biol Ecol 45:245-272

Smith SR (1997) Patterns of coral settlement, recruitment and juvenile mortality with depth at Conch Reef, Florida. Proc 8th Int Coral Reef Symp 2:1197-1202

Editorial responsibility: Charles Birkeland (Contributing Editor), Honolulu, Hawaii, USA
Sokal RR, Rohlf FJ (1995) Biometry. Freeman, New York

Strathmann RR, Branscomb ES, Vedder K (1981) Fatal errors in set as a cost of dispersal and the influence of intertidal flow on set of barnacles. Oecologia 48:13-18

Tougas JI, Porter JW (2002) Differential coral recruitment patterns in the Florida Keys. In: Porter JW, Porter KG (eds) The Everglades, Florida Bay, and coral reefs of the Florida Keys: an ecosystem sourcebook. CRC Press, Boca Raton, p 789-811

Underwood AJ, Keough MJ (2001) Supply-side ecology: the nature and consequences of variations in recruitment of intertidal organisms. In: Bertness MD, Gaines SD, Hay ME (eds) Marine community ecology. Sinauer Associates, Sunderland, p 183-200

Van Moorsel GWNM (1988) Early maximum growth of stony corals (Scleractinian) after settlement on artificial substrata on a Caribbean reef. Mar Ecol Prog Ser 50:127-135

Submitted: July 23, 2003; Accepted: May 8, 2004 Proofs received from author(s): August 27, 2004 